\title{
TEMPOS DE PANDEMIA: EFEITOS DO ENSINO REMOTO NAS AULAS DE QUÍMICA DO ENSINO MÉDIO EM UMA ESCOLA PÚBLICA DE BENJAMIN CONSTANT, AMAZONAS, BRASIL
}

\author{
PANDEMIC TIMES: EFFECTS OF THE REMOTE LEARNING IN HIGH SCHOOL CHEMISTRY CLASSES IN A \\ PUBLIC SCHOOL OF BENJAMIN CONSTANT, AMAZONAS, BRAZIL
}

\author{
TIEMPOS DE PANDEMIA: EFECTOS DE LA ENSEÑANZA REMOTA EN LAS CLASES DE QUÍMICA DE \\ ESTUDIANTES DE SECUNDARIA EN UNA ESCUELA PÚBLICA DE BENJAMIN CONSTANT, AMAZONAS, \\ BRASIL
}

\author{
Agmar José de Jesus Silva ${ }^{*}$ \\ Alcinei Pereira Lopes² \\ Acsa Talita Oliveira da Silva ${ }^{3}$ \\ Arlington da Costa Mauricio ${ }^{4}$ \\ Fabio Fidel da Silva Santana ${ }^{5}$ \\ Carmen Malafaia Silva 6 ic \\ Geiziane Gama dos Santos ${ }^{7}$ ic \\ Isai Ramos Lourenço 8
}

\begin{abstract}
${ }^{1}$ Doutor em Ciências (UFRJ), Professor Efetivo da Seduc/Amazonas, Professor Substituto da Universidade Federal do Amazonas/Instituto de Natureza e Cultura (INC/UFAM), Benjamin Constant, Amazonas, Brasil; ${ }^{2}$ Doutoranda em Química (UFF), Mestra em Química (UFAM), Professora Efetiva da Universidade Federal do Amazonas/Instituto de Natureza e Cultura (INC/UFAM), Benjamin Constant, Amazonas, Brasil; 3,4,5,6,7,8 Graduandos em Licenciatura em Ciências: Biologia e Química do Instituto de Natureza e Cultura da Universidade Federal do Amazonas (INC/UFAM), Benjamin Constant, Amazonas, Brasil; *Autor correspondente: agmarster@gmail.com.
\end{abstract}

Recebido: 08/08/2021 | Aprovado: 06/09/2021 |Publicado: 14/09/2021

\begin{abstract}
Resumo: A pandemia de SARS-CoV-2 atingiu a população mundial em 2020, ceifando milhares de vidas. Para conter a propagação do vírus na fase inicial da doença (COVID-19), medidas rigorosas de saúde como quarentena e distanciamento social foram tomadas pelos governos dos países, seguindo recomendações da Organização Mundial da Saúde. O impacto dessas medidas afetou diversos setores, entre eles a Educação, obrigando instituições de ensino no mundo a fechar as portas e buscar formas alternativas de ensino. Docentes e estudantes precisaram se adaptar rapidamente ao modelo de aulas remotas, o que exigiu mudanças de metodologia de ensino e uso mais intensivo de recursos educacionais digitais. Nesse contexto, esse estudo teve como objetivo avaliar o desenvolvimento do ensino remoto e as dificuldades encontradas no ensino e aprendizagem de Química de um grupo de estudantes do terceiro ano do ensino médio de uma escola pública de Benjamin Constant, AM, Brasil, em 2020. Trata-se de um estudo de caso de abordagem quali-quantitativa, no qual os dados foram obtidos por meio de questionários semiestruturados. Embora o ensino remoto tenha sido aprovado pela maioria desses alunos $(92 \%)$, coexistem alguns obstáculos para uma aprendizagem de fato significativa. Destacam-se a baixa qualidade da rede $4 \mathrm{G}$ local, problemas de acesso a recursos educacionais, e o impacto psicológico e social da pandemia na vida dos estudantes. A questão se mostra ainda complexa e demanda mais investigações pela comunidade escolar e governos, no sentido de se obter um melhor aproveitamento do ensino remoto enquanto este for uma opção viável ao processo educacional.
\end{abstract}

Palavras-chave: Pandemia de COVID-19. Ensino Remoto. Ensino de Química. Tecnologia Educacionais.

Abstract: The SARS-CoV-2 pandemic reached the world's population in 2020, interrupting thousands lives. To break the virus dissemination in the initial phase of the disease (COVID-19), severe health procedures such as quarantine and social distancing were adopted by governments, as per recommendations of the World Health Organization. The impact of these procedures affected several sectors, among them the Education, compelling educational institutions around the world to close its doors and, consequently, to look for alternative forms of education. Teachers and students needed to quickly adapt to the remote teaching model, which required changes in teaching methodology and in the intensity of use of digital educational resources. Hence, this study aimed to evaluate the development of remote teaching as well as its association with the difficulties for Chemistry teaching and learning of a group of 3rd year high school students of a public school in in Benjamin Constant, AM, Brazil, in 2020. This is a case study with a quali-quantitative approach, in which data were obtained through semi-structured questionnaires. Although the remote teaching was approved by majority of these 
students $(92 \%)$, some obstacles coexisted to a truly meaningful learning. Between them are the low quality of the local $4 \mathrm{G}$ network, problems with educational resources, and the psychological and social impact of the pandemic on the students live. The issue is still complex and requires further investigations in order to obtain a better use of the remote teaching while this to mean a feasible option to keep the educational process active.

Keywords: Covid-19 Pandemic. Remote teaching. Chemistry teaching. Educational technology.

Resumen: La pandemia del SARS-CoV-2 afectó a la población mundial en 2020 y cobró miles de vidas. Para contener la propagación del virus en la fase inicial de la enfermedad (COVID-19), los gobiernos establecieron estrictas medidas sanitarias como la cuarentena y el distanciamiento social, según recomendaciones de la Organización Mundial de la Salud. Estas medidas afectaron a diversos sectores, incluido el educativo, lo que exigió a las instituciones educativas de todo el mundo a cerrar sus puertas y buscar otras formas de educación. Profesores y estudiantes necesitaban adaptarse rápidamente al modelo de enseñanza remota, lo que lo que exigió cambios en la metodología de enseñanza y uso de los recursos educativos digitales. Así, este estudio tuvo como objetivo evaluar el desarrollo de la enseñanza remota y las dificultades encontradas en la enseñanza y el aprendizaje de la química de un grupo de estudiantes del tercer año de secundaria de una escuela pública en Benjamin Constant, AM, Brasil, en 2020. Es un estudio de caso con enfoque cualicuantitativo, en que los datos se obtuvieron a través de cuestionarios semiestructurados. Aunque la enseñanza remota fue aprobada por la mayoría de los estudiantes (92\%), coexisten obstáculos para el aprendizaje, como la baja calidad de la red $4 \mathrm{G}$ local, el acceso a los recursos educativos y el impacto psicosocial de la pandemia a los estudiantes. Por lo tanto, el tema aún es complejo y requiere investigaciones adicionales para que se disfrute mejor de la enseñanza remota mientras sea una opción viable para el proceso educativo.

Palabras-clave: Pandemia de COVID-19. Enseñanza remota. Enseñanza de la química. Tecnologia Educacional.

\section{INTRODUÇÃO}

Dados indicam que o SARS-CoV-2 originou-se na China, na cidade de Wuhan (Marques et al., 2020; Mélo et al., 2020). O que inicialmente parecia apenas um surto regional de complicações respiratórias, se espalhou rapidamente, transformando-se em uma pandemia. Atualmente, todos os países estão sendo afetados em seus sistemas de saúde, economia e a rotina das populações (Marques et al., 2020). Essa doença recebeu uma nomenclatura própria em 11 de fevereiro de 2020, pela OMS (Organização Mundial de Saúde), e passou ser chamada COVID-19 (OPAS/OMS Brasil, 2021).

A transmissão do novo Coronavírus acontece de indivíduo para indivíduo, principalmente por gotículas de salivas, espirros ou contato direto com secreções e superfícies contaminadas. Sintomas como febre e tosse são os mais comuns, mas o quadro geral sintomático pode variar para cada pessoa infectada com o SARS-CoV2. A depender do grau de imunidade do organismo, os sintomas podem ser desde leves, como os citados anteriormente, até pneumonia grave, com danos nas funções de órgãos. A COVID-19 tem alta letalidade (até 3\%) (Escobar, Rodriguez, \& Monteiro, 2020) e pode levar à morte se não for controlada, principalmente em grupos de risco, tais como em idosos e pessoas com comorbidades (CEBRIM, 2021).

Como protocolo de proteção, o Ministério da Saúde do Brasil ordenou medidas para contenção da COVID-19, tais como quarentena e distanciamento social, fechamento de escolas e mercados, fechamento de espaços públicos e academias de ginástica, cancelamento de eventos, shows, trabalhos, entre outras. Também foram adotados protocolos de medidas de higiene pessoal, tais como lavagem das mãos com frequência com água e sabão, uso de álcool 70\% nas mãos, cobertura da boca ao tossir ou espirrar, uso de máscara ao sair, 
limpeza da superfície de objetos usados com frequência, e redução do contato com outras pessoas, principalmente com aquelas infectadas (Fiocruz, 2020).

Com a adaptação à nova realidade em decorrência da pandemia, muitos setores foram afetados, não só os sistemas de saúde e a economia mundial, mas também a Educação, em todas as suas etapas. Com as aulas presenciais suspensas, escolas e universidades tiveram que inovar nas formas de ensino, como estratégia dos gestores para amenizar o contágio do novo Coronavírus e ao mesmo tempo não comprometer totalmente o ano letivo de 2020, evitando assim prejuízos acadêmicos aos estudantes. Conforme Nunes (2021), em março de 2020 uma portaria do Ministério da Educação (Portaria n 343/2020) (Brasil, 2020) autorizou a substituição das aulas presenciais por aulas em meios digitais enquanto persistisse a situação de pandemia. Conforme essa portaria:

\footnotetext{
Art. $1^{\circ}$ Fica autorizada, em caráter excepcional, a substituição das disciplinas presenciais, em andamento, por aulas que utilizem meios e tecnologias de informação e comunicação, por instituição de educação superior integrante do sistema federal de ensino, de que trata o art. $2^{\circ}$ do Decreto $\mathrm{n}^{\circ} 9.235$, de 15 de dezembro de 2017.
}

As aulas começaram então de forma remota na maior parte do País. O que não era um ensino comum, onde há a presença de professores e alunos de forma física em uma sala de aula, e nem um Ensino a Distância $(\mathrm{EaD})$, cuja finalidade é promover o encontro entre os alunos e os professores em uma sala virtual, com uso de tecnologias digitais e de práticas docentes voltadas à interatividade. $\mathrm{Na} \mathrm{EaD} \mathrm{"os} \mathrm{pressupostos} \mathrm{básicos} \mathrm{são} \mathrm{a}$ flexibilização do tempo e do espaço, bem como as relações sociais entre os pares, estabelecida a partir do uso de recursos tecnológicos" (Flores \& Do Rosário Lima, 2021, p. 97). Cabe salientar também que os cursos na modalidade EaD demandam tempo e uma série de profissionais envolvidos na sua elaboração (design instrucional, conteudistas, tutores, design gráfico, revisor, entre outros), o que não acontece no ensino remoto, onde as aulas presenciais tiveram de ser adaptadas de maneira abrupta para esse modelo.

Moreira \& Schlemmer (2020, p. 20) apontam que:

[...] o que parece estar a acontecer, neste momento de emergência, é a transferência e a transposição das metodologias e práticas pedagógicas presenciais físicas para os ambientes digitais online. Estão a utilizar-se na maioria dos casos, as tecnologias de webconferência e as plataformas digitais numa perspectiva meramente instrumental, reduzindo as metodologias e as práticas a um ensino e pedagogia magistral.

Nesse aspecto, apesar de sua utilidade como forma de ensino, Flores e Do Rosário Lima (2021) e Moreira, Henriques \& Barros (2020) discorrem que o ensino emergencial (na forma de ensino remoto), da forma que vem sendo realizado não fornece uma educação online com a qualidade necessária, sendo, portanto, passível de fragilidades, uma vez que foi concebido às pressas e sem o estabelecimento das reflexões e análise necessária sobre seu uso. Conforme Moreira, Henriques e Barros (2020, p. 362), entre as necessidades do ensino online, é preciso "definir políticas e criar programas de formação e de capacitação para todos os agentes educativos direcionados para o desenvolvimento de projetos de formação e educação digital que permitam realizar uma adequada transição deste ensino remoto emergencial para uma educação digital em rede de qualidade”. 
Diante do exposto, não apenas as universidades, mas também grande parte das escolas públicas e privadas do País adotaram o ensino remoto emergencial (ERE), utilizando para tal plataformas digitais diversas, tais como WhatsApp, Telegram, Google Meet, Google Classroom, Zoom, Skype, entre outros. Outras ferramentas inusitadas também foram utilizadas, dentre elas, canais de rádio e televisão aberta (Da Silva \& Da Silva, 2021, Bhacana, 2021), tendo em vista que estes constituem meios de comunicação acessíveis à maioria dos estudantes, já que alguns deles não dispõem de aparelho celular com rede $4 \mathrm{G}$ ou computador com acesso à internet.

"Os meios de comunicação e, principalmente a internet, estão alterando as relações entre as pessoas, e atingem os mais diferentes setores da sociedade. Consequentemente, impõem ações diretas e indiretas sobre as práticas dos profissionais da educação" (Forte, 2019, p. 9). A inserção das tecnologias digitais, no Campo da Educação, concebida como ferramenta pedagógica, possibilita ao estudante experimentar o ensino de forma múltipla e aberta, em que eles possam construir interpretações e entendimentos diversos, porém esse resultado depende da forma como o docente irá utilizar essas tecnologias no ambiente de trabalho (Miranda, 2007).

A Química é considerada por muitos estudantes com sendo uma disciplina que apresenta muitas dificuldades de compreensão devido a sua natureza complexa e interdisciplinar (De Jesus Silva \& Da Silva Egas, in press). Segundo Fiori \& Goi, (2020, p. 7) "pensar em alternativas para qualificar os processos de ensino e de aprendizagem em Química é buscar romper essa prática docente promovendo por meio de estudos pautados não só em como se ensina, mas também em como se aprende".

Nessa nova realidade pandêmica, os professores de Química (e das outras disciplinas) foram compelidos a se adaptar ao novo cenário. Essa adaptação incluiu, sobretudo, a adesão ao Ensino Remoto com todas as suas dificuldades, possibilidades, vantagens e desvantagens.

Nesse contexto, os professores precisaram buscar metodologias ativas e/ou diferenciadas que favorecessem o ensino juntamente com emprego mais intensivo de ferramentas tecnológicas digitais disponíveis (Barbosa et al., 2020; Do Nascimento \& Da Rosa, 2021; De Freitas \& Da Silva Santos, 2021, Vercelli, 2020, De Jesus Silva et al., 2019).

Para Forte (2019, p. 4), “Aos profissionais da educação, é preciso que eles procurem inovar em suas metodologias preparando aulas significativas com o uso das tecnologias, e acompanhem o avanço tecnológico, para que haja uma aprendizagem real e significativa".

No Estado do Amazonas, em específico, o governo estabeleceu, a partir da segunda quinzena de março de 2020, um regime especial de aulas não presenciais através da publicação da Portaria GS No 311/2020 da Secretaria de Estado da Educação e Desporto do Amazonas (Seduc-AM) (Da Silva \& Da Silva 2021).

No âmbito do regime especial de aulas não presenciais, uma das principais medidas adotadas pela SeducAM foi a criação do projeto "Aula em Casa". Esse projeto "corresponde a um pacote de atividades pedagógicas e estratégias de ensino que são ofertadas aos professores e alunos da rede pública para apoiar o regime de aulas não presenciais nas unidades escolares" (Seduc-AM, 2021). O “Aula em Casa” foi gestado juntamente com o Conselho Estadual de Educação do Amazonas (CEE/AM), e é executado em parceria com o Centro de Mídias da Educação do Amazonas e a TV Encontro das Águas, que veicula os conteúdos das aulas do ensino 
fundamental $\left(6^{\circ}\right.$ ao $9^{\circ}$ ano) e médio (as três séries) em canais de TV aberta (beneficiando principalmente os estudantes da região metropolitana de Manaus e de cidades próximas).

Outra iniciativa relevante do programa, com extensão de cobertura para todo o estado, foi a criação do aplicativo "Aula em Casa", através do qual os alunos das escolas públicas do Amazonas podem assistir às aulas ao vivo, de maneira interativa e colaborativa com os docentes.

Uma terceira medida igualmente importante e pertencente ao mesmo programa foi a criação dos cadernos digitais do professor e aluno, isto é, um material didático muito rico em conteúdo e cuidadosamente elaborado, em formato digital/e-book, composto por links de acesso a videoaulas, síntese dos conteúdos, dinâmicas interativas, atividades (listas de exercícios), além de orientações didáticas diversas.

Contudo, boa parte dessas ferramentas e recursos educacionais disponibilizados pela Seduc-AM não tiveram a mesma utilidade para os alunos dos municípios do interior do Estado do Amazonas, comparativamente ao público da Capital, Manaus. Esse fato decorre principalmente da péssima qualidade da rede 4G local, a única internet disponível atualmente a estes municípios interioranos do estado. Logo, uma das soluções adotadas pelas equipes gestoras das escolas de interior do Amazonas foi adotar como ferramenta digital de ensino e aprendizagem no período pandêmico o aplicativo Whats App.

Evidentemente, o ensino remoto chegou de forma muito repentina e não planejada, por isso estudá-lo torna-se uma tarefa indispensável aos educadores em nível mundial, e no Amazonas. Na escola em questão, a pesquisa proposta surgiu da busca pela compreensão de que forma o uso das ferramentas tecnológicas poderiam amenizar o impacto da COVID-19 no ano letivo, e quais recursos foram utilizados pelo professor de Química nos momentos antecedentes e posteriores à instalação do período pandêmico.

Nesse contexto, o objetivo dessa pesquisa é avaliar o desenvolvimento do ensino remoto com utilização das tecnologias digitais, e as dificuldades encontradas no ensino e aprendizado de Química de um grupo de estudantes do terceiro ano do ensino médio de uma escola pública de Benjamin Constant/AM, no contexto de impacto pandêmico da COVID-19 ocorrido no ano letivo de 2020.

\section{PERCURSO METODOLÓGICO}

\subsection{Caracterização do estudo}

Este trabalho trata-se de um estudo de caso de abordagem quali-quantitativa. O estudo de caso, segundo Figueiredo \& Souza (2008, p. 120) "é um estudo profundo e exaustivo de fatos, situações ou objetos de maneira que permita seu amplo e detalhado conhecimento". Na abordagem qualitativa "o pesquisador vai a campo buscando obter o fenômeno em estudo a partir da perspectiva das pessoas nele envolvidas, considerando todos os pontos de vista relevantes" (Godoy, 1995, p. 21). Ainda sobre essa abordagem, segundo Neves (1996, p. 10) 
“o autor busca visualizar o contexto, e se possível, ter uma integração empática com o processo objeto de estudo que implique melhor compreensão do fenômeno".

Por outro lado, a pesquisa quantitativa está ligada diretamente ao dado imediato, em que a investigação tem por base a quantificação dos dados e busca medir opiniões e informações utilizando recursos da estatística, tais como porcentagem, média, e desvio padrão, com o objetivo de determinar se as generalizações previstas na teoria se sustentam ou não (Knechtel, 2014).

\subsection{Local de estudo e público-alvo}

O estudo foi realizado na Escola Estadual Imaculada Conceição, localizada no município de Benjamin Constant, na região do Alto Solimões (Estado do Amazonas, Brasil). Contou com a participação de doze estudantes de duas turmas de $3^{\circ}$ ano do ensino médio do turno noturno, e foi marcado por dois momentos principais: anterior e posterior ao início da pandemia da COVID-19 no ano de 2020.

\subsection{Metodologia da pesquisa}

O período anterior à pandemia foi de 1,5 meses de aula, enquanto o pandêmico compreendeu o restante do ano letivo. Conforme informado pelo docente, durante a fase antecedente à pandemia, as aulas foram ministradas de forma presencial, sendo do tipo expositiva e dialogada, com a utilização de recursos audiovisuais (Datashow), elaboração de apostilas impressas, exercícios e trabalhos escolares.

Após o início da pandemia a escola adotou um regime de aulas não presenciais (ensino remoto). Nesse período foram utilizadas metodologias diferenciadas para as aulas de Química, utilizando-se as tecnologias disponíveis. Com uso do aplicativo de celular Whats $A p p$ e a internet $4 \mathrm{G}$ dos aparelhos celulares foram criados grupos das disciplinas, onde eram enviadas periodicamente aos alunos atividades diversas, tais como exercícios, trabalhos, apostilas (em formato digital), podcasts do conteúdo, entre outros.

Durante as aulas, embora a comunicação fosse predominantemente bidirecional e centrada no papel do professor, isto é, de um para muitos (Moreira \& Schlemmer, 2020), havia sempre os momentos para o debate professor/alunos e alunos/alunos, visando dirimir dúvidas do conteúdo em tempo real no espaço do ambiente digital (momento interativo síncrono). Já a interação assíncrona ocorria quando o aluno e professor se comunicavam em tempos diferenciados, ou quando o aluno fazia atividades ou trabalhos escolares a ele enviadas pelo professor. Além disso, aos estudantes que não possuíam aparelho celular com internet, apostilas impressas com os conteúdos das aulas eram entregues nos dias de encontro presencial e individual com a turma (1 aluno por vez, uma vez por semana, em um intervalo total de aproximadamente 2 horas de atendimento).

\subsection{Coleta e análise de dados}


A coleta de dados foi feita através da aplicação de um questionário semiestruturado com 10 Questões, sendo parte destas perguntas abertas (em que o participante estabelece sua opinião e pensamento de forma livre), e outra parte perguntas fechadas (resposta do tipo sim ou não) ou de múltipla escolha (Figueiredo \& Souza, 2008). Os questionários foram aplicados após o término das aulas, isto é, nas últimas semanas do ano letivo de 2020, visando uma coleta de informações mais completas. De acordo com Figueiredo \& Souza (2008, p. 127) questionário é um instrumento de coleta de dados que "consiste basicamente na elaboração de uma série de perguntas ordenadas que traduzem os objetivos específicos da pesquisa em itens redigidos de forma clara e precisa, tendo como base o problema formulado ou a hipótese levantada".

A análise de dados foi descritiva, a qual consiste em descrever as principais tendências nos dados coletados e observar situações que levam a novos fatos (QuestionPro, 2021). De acordo com Gerhardt \& Silveira (2009) uma análise de dados pode envolver aspectos tanto quantitativos (análise estatística, tipos de testes estatísticos escolhidos, etc.) quanto qualitativos (análise de conteúdo, análise de discurso, entre outros).

\section{RESULTADOS E DISCUSSÃO}

\subsection{Metodologias aplicadas antes da pandemia}

O gráfico da Figura 1 apresenta a resposta dos alunos quanto ao percentual de uso de cada uma das metodologias/recursos empregadas pelo docente durante o período em que a pandemia ainda não havia se instalado no município/escola em questão. Esse gráfico, o qual foi gerado a partir das respostas observadas da Questão 1 "Escreva sim ou não acerca dos recursos didáticos/metodologias utilizados pelo professor de Química durante o ano letivo de 2020", mostra que os métodos de ensino mais utilizados pelo docente, segundo os alunos, foram as aulas tradicionais com exercícios (21\%), aulas expositivas com recursos audiovisuais (23\%), apostilas impressas elaboradas pelo professor (23\%), e trabalhos escolares (19\%).

Isso significa que o professor utilizava diferentes metodologias para ensinar Química aos seus alunos, porém as aulas ainda provinham de um método predominantemente tradicional, em que o professor repassa os conteúdos e conhecimentos e os educandos o assimilam de forma passiva. A mediação é feita pelo diálogo em alguns intervalos de tempo, mas com o foco centrado na figura do professor. "[...] É o professor que domina os conteúdos logicamente organizados e estruturados para serem transmitidos aos alunos” (Leão, 1999, p. 9).

Figura 1 - Uso de recursos didáticos/metodologias de ensino pelo professor de Química antes do período pandêmico. 


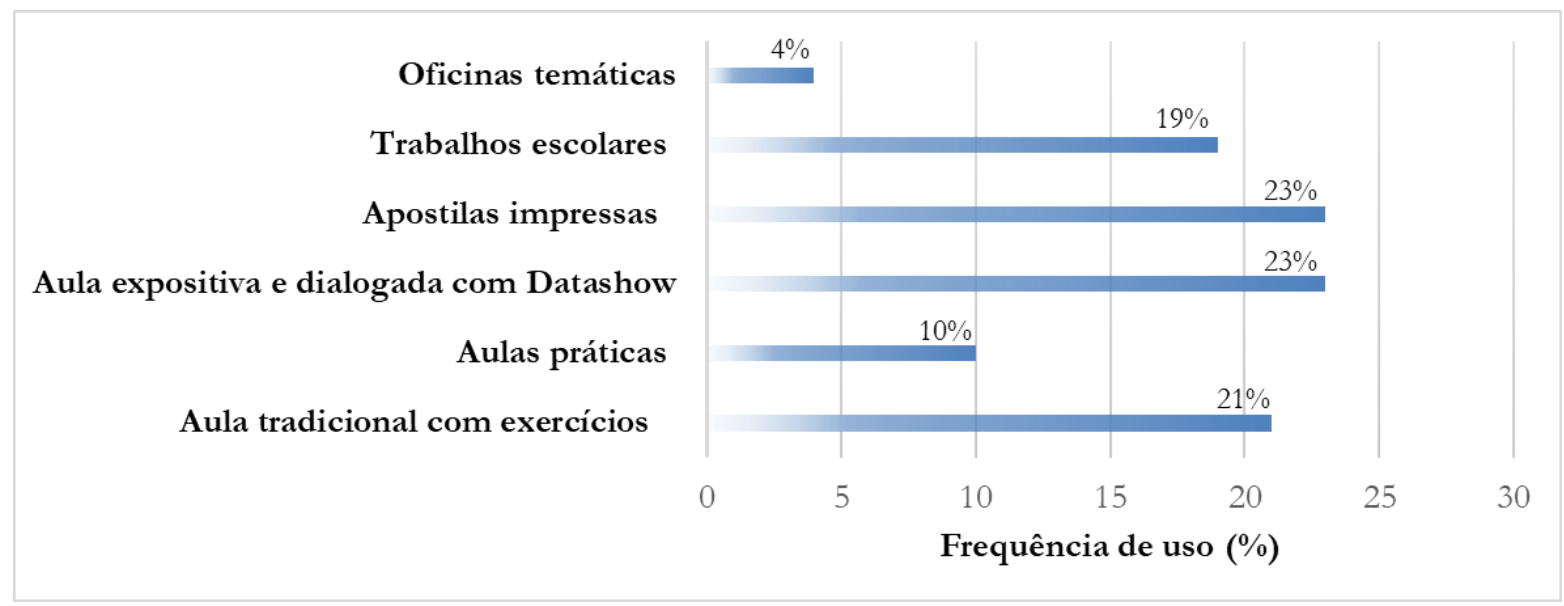

Fonte: Autores (2021).

Contudo, nota-se também a utilização de aula expositiva e dialogada com uso do Datashow e apostilas impressas, resultado da utilização de tecnologias (recursos) disponíveis na escola. Uma aula expositiva e dialogada, como o próprio nome sugere, permite o diálogo entre o professor e os alunos, promovendo o compartilhamento de conhecimentos. Segundo Camargo (2017, p. 16) “essa conexão entre os sujeitos é, essencialmente, constituída na interação e é ela que permite a comunicação de pensamentos, ideias, sentimentos, emoções, saberes, etc.”.

Ainda sobre aula expositiva, Albrecht e Krüger (2021, p. 3) relatam em seu trabalho que "metodologias simples como a aula expositiva, podem ser redescobertas pelo professor, e incorporadas à sua prática cotidiana, com o intuito de proporcionar um ensino de qualidade aos seus alunos". Ou seja, ao utilizar um recurso audiovisual, o educador busca facilitar o aprendizado, tornando o processo educativo mais atraente e dinâmico, pois trata-se de um método de aprendizagem com uso de imagens (Freitas, 2013). Entretanto, "ao ser utilizado como único recurso didático, causa desanimo e indisposição para o aprendizado por parte dos alunos" (Freitas, 2013, p. 13). Logo, é preciso estar atento à diversificação e alternância de metodologias de ensino em sala de aula.

Com relação ao uso das apostilas impressas, o professor busca reforçar ainda mais os conteúdos repassados aos alunos. É uma metodologia aplicada com o intuito de aperfeiçoar a mediação do conhecimento. Para Mota (2015, p. 6), as apostilas impressas “permitem ao aluno transportá-la ou até mesmo acessá-la em lugares bastantes remotos", servindo como base de aprendizagem, além disso, adquirem a oportunidade de desenvolver outras possibilidades de aprendizagem independente. Dessa forma, o uso de apostilas não substitui o livro didático, mas é visto como um complemento para que o estudante não fique limitado apenas aos conhecimentos do livro, e sim obtenha mais informações sobre assuntos estudados.

O gráfico da Figura 2, gerado a partir das respostas dos alunos sobre a Questão 2: "Qual a sua maior dificuldade em aprender Quimica?”, quando comparado ao gráfico da Figura 1, confirma a escassez de aulas práticas realizadas pelo professor, onde se observa que apenas 10\% dos alunos afirmaram ter tido aulas práticas. Ao mesmo tempo, 50\% dos alunos (Figura 2) afirmam que a ausência de aulas práticas faz aumentar suas 
dificuldades na aprendizagem da disciplina de Química. Por outro lado, 8,3\% aparentam simplesmente não gostar da disciplina, enquanto outros $8,3 \%$ apresentam pouca ou nenhuma dificuldade de aprendizagem, sendo estes os alunos de maior desempenho da turma.

Figura 2 - Dificuldades de aprendizagem de Química apresentadas pelos alunos.

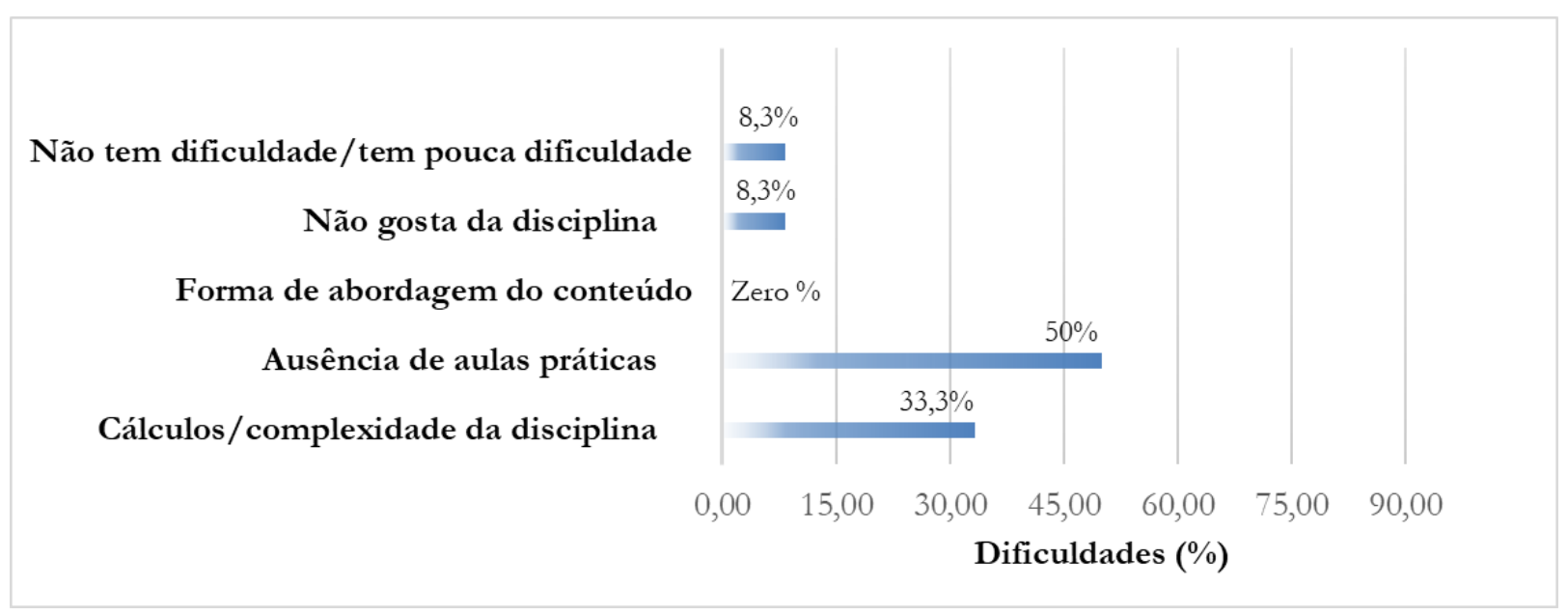

Fonte: Autores (2021).

É de conhecimento comum nas escolas e academias, que a Química é uma ciência interdisciplinar. Além disso, muitas vezes é vista pelos alunos de forma muito abstrata, demandando dedicação e atenção de quem a estuda. Conforme Santos Neto, Almeida e Feitosa (2018, p. 129) "a química faz parte das ciências da natureza, sendo uma ciência empírica ensinada de maneira abstrata, porque necessita constantemente que os professores e os alunos estejam imaginando situações práticas de conceitos abstratos”. E segundo Belo, Leite e Meotti (2019, p. 2) "a química exige conhecimentos de outras disciplinas das exatas, como a matemática e física".

Diante disso, nota-se o quão importante é a realização de aulas práticas no ensino de Química, pois esse tipo de aula funciona como forte aliada à compreensão e ao aprendizado dos conteúdos dessa Ciência por parte dos alunos. Estes, ao entrarem em contato com experiências de Química no ambiente laboratorial, estimulam e ativam seu desenvolvimento cognitivo, melhorando assim a capacidade de associação entre conceitos químicos e os fatos e/ou processos do mundo real, o que lhes proporciona uma aula mais interessante e que desperta a sua curiosidade e vontade de aprender.

De acordo com Silva (2016, p. 21) “a experimentação, como aula prática, torna-se indispensável para o processo de ensino e aprendizagem de conceitos científicos, pois favorece a construção das relações entre a teoria e prática, assim como as concepções dos alunos e novas ideias a serem desenvolvidas”. Para Salasse (2012, p. 17-18), "ela permite que os alunos manipulem objetos e negociem significados entre si e com o professor durante a aula. É importante que as aulas práticas sejam conduzidas de forma agradável para que não se tornem uma competição entre grupos e, sim, uma troca de ideias e conceitos ao serem discutidos os resultados".

É provável que, na escola em questão, o docente não tenha tido tempo suficiente para iniciar a programação de aulas práticas de seu plano de ensino, pois as aulas iniciaram em 05 de fevereiro de 2020, e já 
em meados de março estava decretado e estado de pandemia de COVID-19, impossibilitando qualquer atividade educacional nas instalações da escola. Por esse motivo, em estudos posteriores seria interessante indagar o docente sobre seu planejamento de ensino quanto à inclusão das aulas práticas experimentais, e qual a sua visão sobre a importância destas para o desenvolvimento escolar dos estudantes.

Ainda sobre as dificuldades dos alunos, apresentadas na Figura 2, nota-se que 33,3\% dos estudantes têm dificuldades em Química por conta dos cálculos matemáticos e complexidade da disciplina. Isso é uma questão muito preocupante devido ao caráter interdisciplinar intrínseco da Química. Ou seja, é preciso que os alunos do ensino médio tragam das aulas de matemática e física um domínio mínimo de cálculos algébricos e habilidades com operações numéricas. Em seu trabalho, Santana (2021, p. 22) relata que "é fato que a incapacidade de absorção do conteúdo, quando a deficiência da aprendizagem se encontra no desconhecimento de meras operações básicas de matemática e interpretação de texto, impede que o aluno compreenda os assuntos, dando a falsa compreensão de complexibilidade". Nesse contexto, é notável que a incompreensão e a falta de conhecimento de outras áreas também são fatores que impedem os estudantes de ter bom desempenho e entender os conceitos químicos mais rapidamente. Nesse sentido, cabe aos docentes, juntamente com a equipe pedagógica da escola, traçar metas e objetivos que visem sanar tais dificuldades nestes alunos antes que eles concluam seus estudos de nível médio levando consigo essas deficiências de formação.

No sentido de sanar tais problemas, é fundamental também que cada educador busque em seus métodos formas de reduzir as dificuldades dos alunos. No caso da Química, há uma grande variedade de opções de ensino que incluem metodologias ativas e diferenciadas que podem facilitar a aprendizagem dos conteúdos, aproveitando o conceito de interdisciplinaridade e introduzindo, por exemplo, aulas práticas experimentais contextualizadas. Para Santana (2021), a pouca exploração da interdisciplinaridade da disciplina e o emprego contínuo de um único método do ensino pode dificultar a compreensão da Química. Entretanto, mesmo que o docente busque aplicar métodos diferenciados para amenizar essas lacunas no aprendizado, o despreparo e a falta de infraestrutura laboratorial nas escolas são desafios que precisam ser superados. De Jesus Silva \& Da Silva Egas (2021, in press) reportam que nem mesmo a falta de estrutura laboratorial deve ser tida como barreira intransponível para a realização de aulas práticas experimentais, uma vez que "algumas experiências podem acontecer inclusive em sala de aula, resguardados os devidos cuidados".

Ainda com relação ao período antecedente ao surgimento da pandemia, a Questão 3 indagou os alunos sobre a opinião deles em relação ao desenvolvimento da aula presencial expositiva e dialogada com uso de recurso audiovisual: Questão 3: "No período que anteceden a pandemia de COVID-19 (fevereiro a março de 2020), o uso de aula presencial expositiva e dialogada com recursos audiovisuais (Datashow) facilitou sua aprendizagem de quimica?". Sobre a aula expositiva em si, os estudantes responderam:

Aluno 2: "Sim. Aprendemos mais vendo aula e o professor explica bem".

Aluno 3: "Sim. Pela explicação e exemplo que mostrava". 
Aluno 4: "Não. Porque eu prefiro as explicaçoes do professor, mas sem ter o Datashow".

Aluno 9: "Sim. A gente tinha a explicação melhor do professor"

Aluno 12: "Sim. Com ajuda do professor tudo se tornava mais fácil na explicaşão".

Observa-se que a utilização do Datashow é vista como um ponto positivo e que facilita o aprendizado dos educandos, tal como discutido anteriormente. Nota-se o destaque que a maioria dos alunos deu às explicações do professor sobre os conteúdos, as quais eram feitas de forma que todos entendessem bem o assunto. Isso significa que, fazendo o uso de metodologias diferenciadas nessa escola, o professor buscava fazer com que seus alunos entendessem os fenômenos químicos ocorrentes em sua volta, exercendo assim um importante papel de mediador da aprendizagem em sala de aula.

Ademais, outro ponto positivo que pode ser notado nas respostas dos alunos é a utilização de imagens digitais durante a apresentação da aula expositiva com Datashow:

\section{Aluno 5: "Sim. Pois fica melhor entender, pois além do professor explicar também podemos ver imagens e entender melhor" \\ Aluno 7: "Sim. Porque nos mostrou imagens que ilustram a aprendizagem" \\ Aluno 8: "Sim. Porque era bem explicada e podemos ver as fórmulas claramente".}

As imagens são fundamentais no ensino quando comparadas aos textos. No entanto, não faz sentido sua comparação ao texto quanto à finalidade no ensino, pois os dois recursos não se anulam, pelo contrário, se complementam constituindo importantes meios de comunicação voltados à construção dos saberes (Laia, 2016). Nesse contexto, nota-se que os estudantes relacionam os conceitos teóricos com as imagens apresentadas, tornando o conteúdo mais compreensível e fácil de entender, e assim adquirindo um aprendizado significativo. E o professor, ao explicar o assunto, se torna a "ponte" entre o aluno e o conteúdo apresentado na imagem. Segundo Laia (2016, p. 8):

O professor é responsável pela mediação entre o aluno e a imagem. É ele quem a seleciona para uso e escolhe a maneira mais adequada de explorar essa imagem com seus alunos, proporcionando a eles novos conhecimentos, formação de conceitos, significados e uma nova forma de aprender a ler o mundo, ou seja, alfabetizar-se visualmente.

Na química é importante o uso de imagens por se tratar de uma disciplina que estuda um universo desde o submicro até ao macroscópico, envolvendo conceitos teóricos complexos, tais como átomos, moléculas, elementos químicos, fórmulas químicas, equações e reações químicas, entre outros. Além de facilitar o aprendizado, as imagens são acessíveis e gratuitas, facilitando o trabalho do professor ao elaborar suas explicações de maneira mais clara, e podem ser memoráveis para quem as visualiza e interpreta. Nota-se que o método da aula expositiva com utilização de recursos audiovisuais tornou as aulas mais interessantes para os educandos, como é visto nesta resposta:

Aluno:10 "Sim. Tornou a aula mais interativa, chamativa e divertida". 


\subsection{Metodologias aplicadas após o início da pandemia}

Em reposta à Questão 4, "2020 foi um ano totalmente atípico. Você contraiu a COVID-19 nesse ano?”, verificouse que $42 \%$ dos estudantes participantes da pesquisa contraíram a COVID-19 em 2020, o que é um percentual considerável tendo em vista o alto grau de letalidade da doença em questão. Esse resultado comprova a gravidade do cenário pandêmico de COVID-19 estabelecido em 2020 também no município em questão. Felizmente, as autoridades competentes tomaram ciência dos fatos em tempo hábil e estabeleceu-se o regime de isolamento social. No campo da educação, tal medida implicou na adoção do ensino remoto para as atividades escolares no município de Benjamin Constant, de modo similar ao ocorrido na maior parte do País.

Dessa forma, o professor teve que buscar ferramentas de auxílio ao em ensino, de modo que suas aulas de Química fossem proveitosas para os estudantes mesmo em um cenário de difícil atuação, como é o caso do ensino remoto em uma região com tantos problemas estruturais e socioeconômicos. No gráfico da Figura 3 estão representados os resultados obtidos a partir das respostas dos alunos à Questão 5: “Após o início da pandemia, a escola estabelecen um regime de aulas não presenciais (ensino remoto). Qual foi a principal metodologia adotada pelo professor de Quimica nesse período?":

Observa-se pela Figura 3 que 67\% dos alunos afirmam que a alternativa mais utilizada pelo professor após o estabelecimento da pandemia foi "Apostilas digitais com tutoria pelo Whats App". Adicionalmente, cerca de 13\% afirmam que foi utilizado "Exercício do livro com tutoria do professor pelo Whats App", e 20\% "Trabalhos escolares". Esse resultado evidencia que o Whats $A p p$ foi a ferramenta/recurso de ensino e aprendizagem que apresentou melhor resultado, no sentido de permitir aos alunos a continuidade de seus estudos a partir de suas próprias residências e, dessa forma, mais protegidos do contágio pela COVID-19.

Figura 3 - Métodos utilizados pelo docente de Química após o início do período pandêmico.

- Aulas por videoconferência $($ zero $\%)$

- Exercícios do livro com tutoria do professor pelo WhatsApp

- Apostilas digitais com tutoria pelo WhatsApp

" Trabalhos escolares

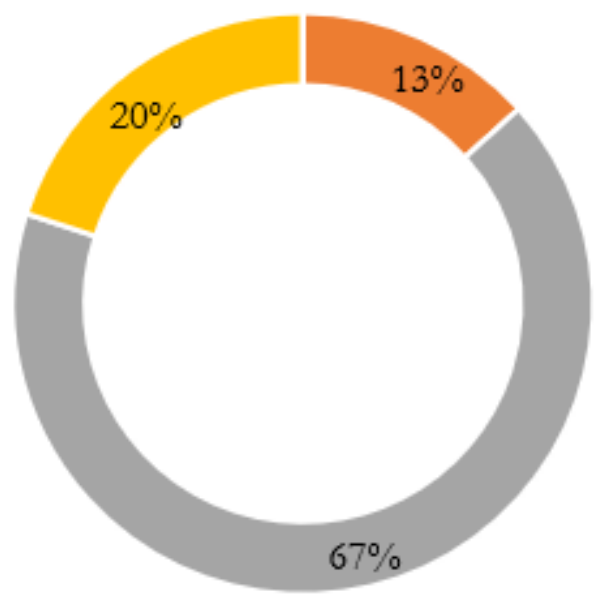

Fonte: Autores (2021). 
Observou-se que, mesmo com todas as dificuldades recorrentes de conexão à internet na região, o Whats App ainda assim foi o recurso educacional que permitiu o acesso às aulas remotas pela maioria dos alunos. Embora a maioria dos estudantes envolvidos na pesquisa tenham declarado não possuir computador com internet em suas casas (Figura 4a), os mesmos alunos confirmaram possuir o aplicativo Whats App instalado nos seus aparelhos celulares com acesso à internet (Figura 4b). Segundo Lima \& Ferrete (2020, p. 5):

Através do Whats App se compartilham dúvidas e aprendizagens, pois pode ser um espaço pensado com o objetivo de promover a construção de conhecimento do grupo e que consegue envolver várias pessoas no processo de aprendizagem.

Figura 4 - a) Respostas dos alunos à Questão 6 ("Você tinha computador em casa com acesso à internet no ano de 2020").

b) Respostas à Questão 7 ("Você tinha aparelho celular com acesso à pacote de internet e ao Whats App no ano de 2020?").
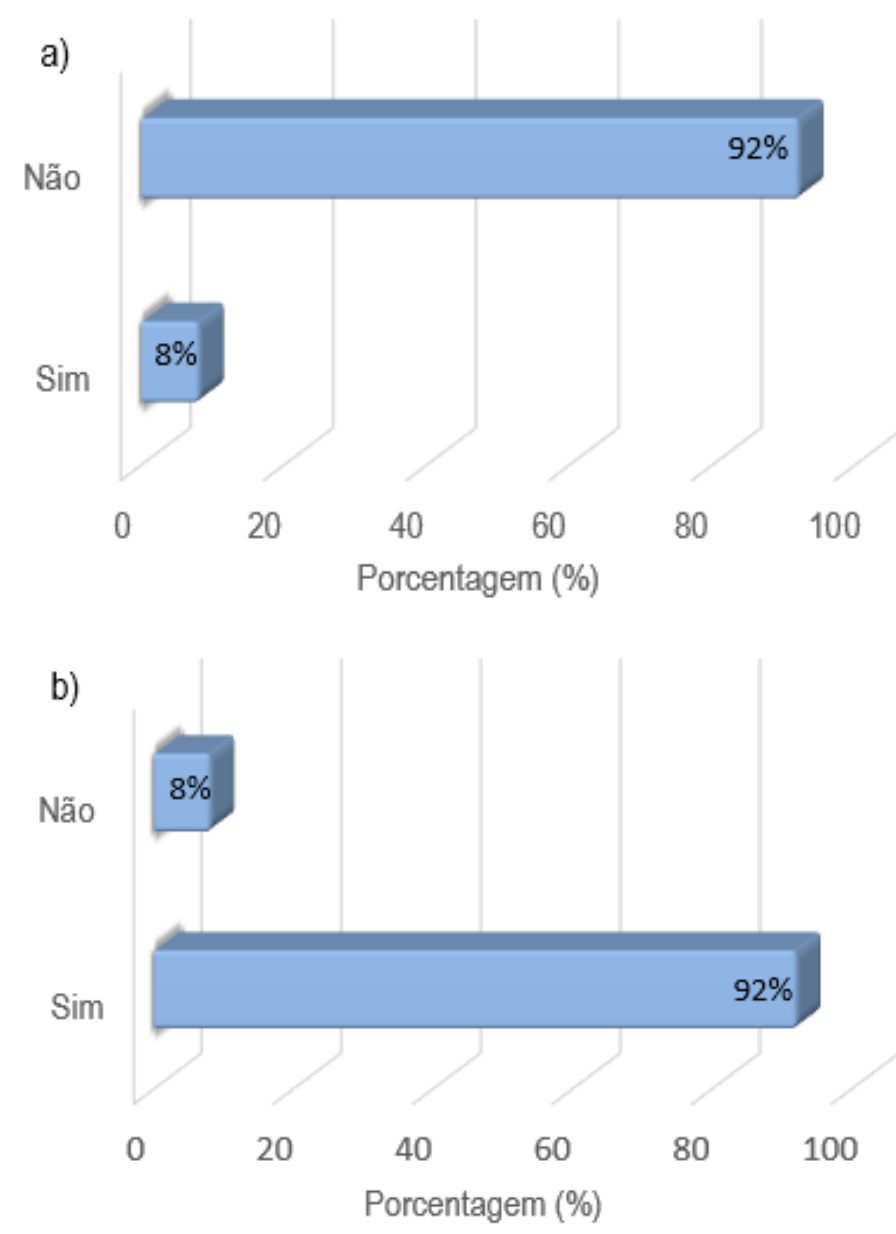

Fonte: Autores (2021).

O aplicativo Whats App permite aos alunos ter acesso aos conteúdos na forma tanto online quanto offline, e quantas vezes forem necessárias, pois os conteúdos ficam disponíveis a qualquer momento após o download inicial. Esse fato contribuiu bastante no sentido de apoiar o processo de ensino e aprendizagem, seja na forma coletiva ou individual. Ainda, segundo Lima e Ferrete (2020, p. 6): 


\begin{abstract}
Neste sentido, o Whats App traz grande potencial transformador no que se refere a continuidade das atividades escolares, desde que haja um bom planejamento. Ao adotar um grupo nesse aplicativo com finalidade de apoio pedagógico, o professor abre um espaço para que seus estudantes embarquem em situação de interatividade, possibilitando que todos possam aprender.
\end{abstract}

Dessa forma, observou-se que o aplicativo Whats $A p p$ contribuiu bastante como o processo de ensino e aprendizagem desses estudantes mesmo durante as fases mais críticas do isolamento social no auge da pandemia. Ademais, o uso das apostilas digitais juntamente com os recursos do Whats App constituiu numa metodologia interessante no sentido de permitir aos estudantes acesso rápido e contínuo aos conteúdos disponibilizados, os quais eram apresentados pelo docente de forma objetiva e simplificada. Assim, essas apostilas foram úteis também no sentido de manter os alunos interessados, ativos e envolvidos com o conteúdo, evitando assim aumento do desestímulo e da evasão estudantil nesse período de dificuldades.

Em resposta à Questão 8: "Com relação ao uso de apostilas elaboradas e impressas pelo professor, estas eram bem elaboradas e de fácil compreensão?", todos os estudantes responderam "Sim”. Isso significa que o esforço do professor foi reconhecido pelos alunos. E esse trabalho do professor ao planejar aulas remotas não era tarefa fácil. Logo, saber que os seus alunos estavam compreendendo o assunto através das apostilas com a tutoria online foi um incentivo à continuidade e aperfeiçoamento do trabalho realizado. Lima \& Ferrete, (2020, p. 3) reportam:

A inserção de ferramentas digitais pode contribuir significativamente para que os estudantes desenvolvam habilidades e competências compatíveis com as demandas sociais vigentes, construindo um percurso próprio de aprendizagem a partir das suas necessidades.

Dessa forma, observa-se o papel fundamental que o docente exerceu na mediação do conhecimento científico e na condução do processo de ensino e aprendizagem dos estudantes. Isto é, mesmo as aulas sendo realizadas de forma remota, o professor continuou sendo o elo facilitador que permitiu a compreensão dos alunos acerca dos conteúdos ministrados por meio das apostilas digitais ou impressas. Como discutido anteriormente, o professor também utilizou essa metodologia nas aulas presenciais para que os conteúdos fossem melhor assimilados pelos estudantes, e o resultado já se mostrava promissor desde então.

O gráfico da Figura 5 apresenta as respostas dos alunos em relação à Questão 9: "O professor corrigia e devolvia as atividades das apostilas?". Nota-se que 92\% deles afirmam que o professor corrigia e devolvia as atividades das apostilas com os respectivos feedbacks e, segundo 8\%, a devolutiva das apostilas ocorria apenas as “às vezes”. Em todo caso, ficou evidenciado o compromisso e a responsabilidade do professor com seus educandos no que tange ao seu papel como mediador e instrutor do conhecimento mesmo em tempos de tantas dificuldades operacionais. O feedback foi uma ferramenta importante utilizada pelo professor no ensino remoto. De acordo com Santos (2020) "é uma ferramenta de comunicação entre professores e alunos que contribui para a reflexão de ambos a respeito do que o estudante é ou não capaz de realizar e aprender". Os exercícios e 
trabalhos permitem aos alunos revisar conceitos, aprofundar os estudos, firmar o conhecimento acerca das fórmulas e conteúdos, e fazem com que os estudantes consolidem os saberes-fazeres ensinados.

No contexto pandêmico, realizar a devolutiva das atividades aos alunos foi um desafio, pois dificuldades como a falta de internet de qualidade, cumprimento do distanciamento social, e a ausência de contato visual dificultavam um bom feedback. No entanto, de acordo com as respostas dos alunos, o feedback foi realizado mesmo nesse cenário calamitoso, o que lhes proporcionou um desempenho razoável nas atividades durante o período remoto.

Figura 5 - Devolutiva e feedbacks das atividades de apostilas.

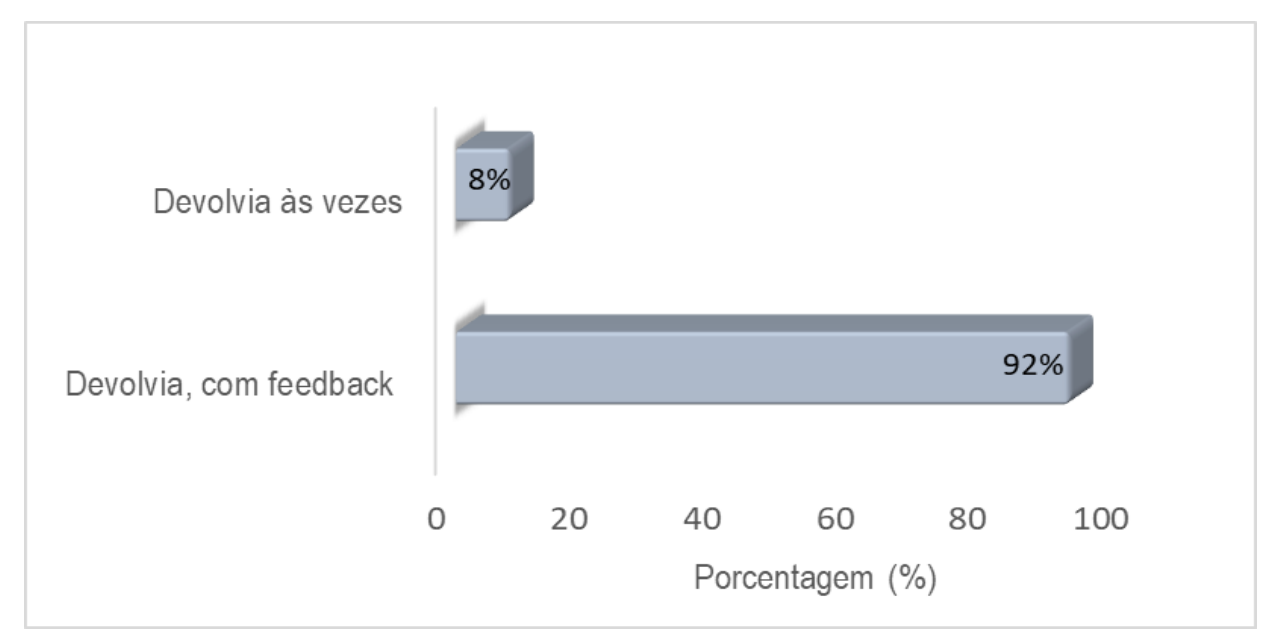

Fonte: Autores (2021).

A Questão 10 fez a seguinte indagação aos estudantes: "V ocê avalia positivamente o esforço realizado pela equipe de sua escola (gestor, pedagogo e professor) para salvar o ano letivo de 2020?”. Também nesse caso, 92\% avaliaram positivamente o esforço da escola para conduzir e encerrar o ano letivo em meio ao cenário pandêmico. Foi quase unânime o reconhecimento do esforço realizado pela equipe escolar no ensino remoto, pois foi necessário um desdobramento de todos: estudantes, professores, pedagogo e gestor, no sentido de evitar prejuízos escolares ainda maiores a estes estudantes no letivo de 2020. Segundo Lima e Ferrete, (2020, p. 3), “contudo, neste novo cenário, os desafios postos foram além das limitações de muitas escolas por exigir a participação de toda a comunidade escolar para que não houvesse descontinuidade do ano letivo por longo período”.

Portanto, observa-se que a escola em questão teve um grande compromisso com a educação dos seus estudantes. Essa equipe escolar viabilizou, realizou, incentivou e criou soluções para que os professores ministrassem suas aulas sem prejudicar tanto o desenvolvimento do período letivo. Sabe-se que tanto a comunidade escolar quanto os alunos precisaram se adaptar às inovações da tecnologia como ferramenta didática, o que não foi tarefa fácil para nenhum dos lados. Muitos professores não possuíam o conhecimento completo do funcionamento de algumas tecnologias. Então, a escola precisou atuar orientando seus educadores 
para essa nova experiência que foi ministrar aulas através dos meios digitais, sendo de extrema importância o planejamento da escola para que os alunos não se prejudicassem ainda mais nesse período de ensino remoto.

\subsection{Efeitos psicossociais}

Não há como fazer uma análise coerente do ensino remoto em qualquer estabelecimento de ensino que seja sem levar em conta os aspectos psicológicos e sociais das vidas daqueles envolvidos no processo educacional: docentes, estudantes, e famílias dos estudantes. Em municípios do interior do Amazonas, como é o caso de Benjamin Constant, a situação foi e ainda continua sendo crítica, pois muitos estudantes do interior não têm as condições mínimas necessárias para acompanhar o ensino remoto, isto é, equipamentos e internet de qualidade, espaço físico adequado para estudo, apoio familiar e disponibilidade de tempo, tal como relatado por Da Silva e Da Silva (2021). Ademais, muitas famílias brasileiras, e não apenas amazonenses, tiveram sua situação econômica deteriorada durante o período pandêmico (De Oliveira Gomes, 2021), agravando ainda mais a falta de motivação dos estudantes dessas famílias em se mantarem ativos na sua formação escolar.

No caso dos alunos do turno noturno da escola em questão, é de conhecimento da equipe gestora e professores que parte significativa desses alunos são pais e mães e, portanto, trabalham durante o dia para manter o sustento de suas próprias famílias. Dessa forma, o tempo de permanência na escola torna-se o momento mais valioso que estes estudantes têm para desfrutar de uma aprendizagem mais significativa. Não havendo esse contato no período de distanciamento social, e pressionados por problemas de baixa renda e desemprego causados pelo isolamento das famílias durante a pandemia, muitos desses estudantes ficaram sujeitos ao desenvolvimento de alterações emocionais comprometedoras do bem estar físico e mental, tais como angústia, medo, falta de concentração, ansiedade, depressão, estresse, entre outros fatores de cunho físico e/ou psicológico, culminando em desestímulo pelos estudos e, consequentemente, abandono escolar, elevando o índice de evasão (Nunes, 2021; De Oliveira Paz et al., 2021).

Esse quadro era ainda mais agravado nas famílias de estudantes onde uma pessoa ou duas ou até mesmo toda família era acometida pela doença e suas sequelas posteriores (isso quando não ocorria o falecimento). Dessa forma, é evidente que se configurou um quadro clínico e psicossocial complexo pós-contágio com a COVID-19, o qual ainda ocorre mesmo atualmente, haja vista que a vacinação reduziu o número de contaminações e mortes pela doença, mas ainda não controlou totalmente a pandemia. Nesse contexto, Da Silva e Da Silva (2021, p. 31) relatam ser indispensável que "As respostas no campo da educação devem considerar a complexidade e o grande desafio que é promover o direito a educação em um contexto de intensa desigualdade social. Isto é possível tomando contato com as pessoas e suas vidas”.

Não obstante a problemática causada pela pandemia na rotina dos estudantes e de suas famílias, os professores também sofreram impactos consideráveis. Conforme Da Silva e Da Silva (2021, p. 30): 
Em relação aos docentes, as dificuldades relatadas envolvem queixas em relação ao aumento da carga de trabalho, aumento dos gastos com energia elétrica e internet, cobranças excessivas dos gestores escolares, aumento da carga de trabalho doméstico, alterações no sono e apetite, alterações emocionais. Todas/os docentes relataram algum impacto emocional decorrente das incertezas e ameaças devido ao medo de adoecer, ao luto pelas perdas de entes queridos.

No caso da Escola Estadual Imaculada Conceição, soma-se a isso a dificuldade de mediação pedagógica que os docentes tinham ao ensinar os conteúdos pelo ambiente virtual do Whats $A p p$ (principal recurso digital empregado), pois alguns alunos não tinham acesso aos grupos por não terem o equipamento (aparelho celular), ou por não possuírem condições financeiras de manter o celular com internet para acesso às aulas e conteúdos diários postados pelos professores. Mesmo quando tinham acesso, alguns alunos aparentemente não se sentiam confortáveis em expor suas opiniões e questionamentos no ambiente virtual, o que era evidenciado pelo baixo grau de interação e de diálogo desses estudantes com o docente nos grupos virtuais durante o período de atendimento síncrono.

\section{CONSIDERAÇÕES FINAIS}

Os impactos da pandemia do COVID-19 foram danosos à população mundial. Entes queridos foram perdidos e a saúde das pessoas afetada. A economia foi prejudicada, as pessoas foram abaladas psicologicamente. A luta de profissionais de saúde para salvar vidas foi intensa. Ao mesmo tempo, instituições de ensino no mundo todo precisaram se readaptar à nova realidade escolar para concluir o ano letivo de 2020.

A realização dessa pesquisa revelou a "radicalidade" na mudança de rotina ocorrida nesse período pandêmico no âmbito da escola avaliada, a Escola Estadual Imaculada Conceição. O uso das tecnologias digitais pelo professor foi essencial para a manutenção do ensino, com destaque para o aplicativo Whats App. Essas tecnologias foram a principal via de trabalho que permitiu o andamento do ano letivo poupando vidas, isto é, evitando a contaminação dos membros da comunidade escolar pela COVID-19.

Entretanto, as dificuldades vivenciadas foram muitas, desde problemas com acesso à internet e equipamentos apropriados, problemas financeiros dos alunos e suas famílias, até problemas de cunho psicológico em toda a comunidade escolar. Ademais, não foi nada trivial a transposição emergencial do modelo de ensino presencial para os moldes do ensino remoto. Esse processo exigiu um extenuante esforço por parte de toda comunidade escolar, isto é, gestores, pedagogos, docentes, estudantes e famílias dos estudantes. Nesse contexto, o professor precisou mostrar flexibilidade e capacidade de adaptação às novas mudanças no âmbito escolar e educacional, além de que foi necessária uma dedicação de tempo e união de esforços em nível acima do usual para atingir as metas do ensino remoto na escola em questão.

Para a aprendizagem de Química, a aceitação do ensino remoto foi positiva nas turmas avaliadas, mas claramente muitos problemas persistem envolvendo questões tanto socioeconômicas quanto psicológicas. É 
certo que o caminho ainda será longo pela frente até a superação total dos danos materiais, psicológicas e de formação provocados por essa doença na vida dessa geração de estudantes.

Como perspectiva futura, de certa forma o ensino remoto parece ter acelerado a chegada de uma tendência educacional moderna que já vem se consolidando há algum tempo, o ensino híbrido ou Blended Learning (Neto, 2017). Esse formato educacional vem instigando discussões e reflexões entre professores, gestores e equipes pedagógicas, no afã de entender como este deve ser executado, e quais são os seus potenciais benefícios à comunidade estudantil. O que já é de consenso comum sobre esse formato é a forte integração de tecnologias digitais no processo educacional e a personalização do ensino, isto é, o estudante passa a ser colocado no centro do seu processo de aprendizagem, tornando-se o maior protagonista do seu desenvolvimento e sucesso escolar.

\section{Agradecimentos}

Agradecemos aos estudantes da Escola Estadual Imaculada Conceição de Benjamin Constant/AM pela prestatividade em responder o questionário de maneira totalmente voluntária. Agradecemos também ao grupo de estudantes da disciplina de Redação Científica (INQ106) do curso de Licenciatura em Ciências: Biologia e Química do INC/UFAM que aceitaram o desafio de contribuir na escrita desse manuscrito sobre um tema tão impactante na vida atual da população mundial.

\section{Conflitos de interesses}

Os autores declaram que não há conflitos de interesse. Todos os autores estão cientes da submissão do artigo.

\section{REFERÊNCIAS}

Albrecht, L. D., \& Krüger, V. (2013). Metodologia tradicional x Metodologia diferenciada: a opinião de alunos. Encontro de Debates sobre o Ensino de Quimica, Ijuí: Unijui.

https://www.publicacoeseventos.unijui.edu.br/index.php/edeq/article/view/2735/2311

Barbosa, A. M., Viegas, M. A. S., \& Batista, R. L. N. F. F. (2020). Aulas presenciais em tempos de pandemia: relatos de experiências de professores do nível superior sobre as aulas remotas. Revista Augustus, 25(51), 255-280. https://doi.org/10.26843/ae19828632v13n22020p47a60

Belo, T. N., Leite, L. B. P., \& Meotti, P. R. M. (2019). As dificuldades de aprendizagem de química: um estudo feito com alunos da Universidade Federal do Amazonas. Scientia Naturalis, 1(3), 1-9.

https://peridiocos.ufac.br/index.php/Scinat/article/view/2540/1448

Bhacana, M. (2021). Benjamin Constant (AM) inicia projeto "Rádio Escola" para minimizar impactos da pandemia na educação. Jornal OTAMBAQUI. https://otambaqui.com.br/benjamin-constant-am-inicia-projetoradio-escola-para-minimizar-impactos-da-pandemia-na-educacao/ 
Brasil. (2020). Portaria n. ${ }^{\circ}$ 343, de 17 de março de 2020. Dispõe sobre a substituição das aulas presenciais por aulas em meios digitais enquanto durar a situação de pandemia do Novo Coronavírus - COVID-19.

Camargo, A. F. (2017). O diálogo na relação professor-alunos: a complexa trama das interações no cotidiano da aula no ensino médio. Dissertação (Mestrado em Educação) - Programa de Pós-graduação em Educação, Universidade de Passo Fundo, Passo Fundo.

Centro Brasileiro de Informação sobre Medicamentos (CEBRIM). (2020). Coronavírus. https://www.cff.org.br/userfiles/Coronavirus $\% 20-\% 20 \% 20$ Folder.pdf

Da Silva, I. R., \& Da Silva, C. R. (2021). O projeto “Aulas em Casa” e a educação remota durante a pandemia do COVID-19: análise da experiência do estado do Amazonas. Revista Educar Mais, 5(1), 25-34.

https://doi.org/10.15536/reducarmais.5.2021.2220

De Freitas, F. A. M., \& Da Silva Santos, E. (2021). Os entraves do ensino remoto para a formação acadêmica no curso de Ciências - Biologia e Química no IEAA/UFAM. Revista Prática Docente, 6(1), e018.

http://10.23926/RPD.2021.v6.n1.e18.id1020

De Jesus Silva, A. J., De Sousa, B. M., \& De Jesus Silva, A. J. (2019). Planificações de sólidos: aplicação como intervenção pedagógica de baixo custo para o ensino de conceitos geométricos para alunos de uma escola de ensino fundamental no oeste do Pará. South American Journal of Basic Education, Technical and Technological, 6(2), 168189. https://revistas.ufac.br/index.php/SAJEBTT/article/view/2798

De Jesus Silva, A. J., \& Da Silva Egas, V. S. (2021). Percepção da importância do uso de atividades experimentais na aprendizagem de química de um grupo de estudantes concluintes do ensino médio em uma escola pública em Tefé/AM. Revista Insignare Scientia-RIS, In press.

De Oliveira Gomes, J. (2021). Educação e pobreza: uma construção histórico-social. Journal of Education Science and Health, 1(2), 1-16. https://doi.org/10.52832/jesh.v1i2.15

De Oliveira Paz, M. S., De Almeida, N. R., De Araújo, J. P., \& Ramos, A. M. (2021). Envolvimento dos discentes nas atividades escolares em tempos de pandemia do COVID-19: Ações desenvolvidas pelo o IFPACampus Paragominas. Research, Society and Development, 10(3), e36310313470.

http://dx.doi.org/10.33448/rsd-v10i3.13470

Do Nascimento, F. G. M., \& Da Rosa, J. V. A. (2020). Princípio da sala de aula invertida: uma ferramenta para o ensino de química em tempos de pandemia. Brazilian Journal of Development, 6(6), 38513-38525.

https://doi.org/10.34117/bjdv6n6-409

Eleva Plataforma (2021). Metodologia de Ensino: tudo o que voce precisa saber sobre o tema. https://blog.elevaplataforma.com.br/metodologia-de-ensino

Escobar, A. L., Rodriguez, T. D. M., \& Monteiro, J. C. (2020). Letalidade e características dos óbitos por COVID-19 em Rondônia: estudo observacional. Epidemiologia e Serviços de Saúde, 30 (1), 1-10.

http://dx.doi.org//S1679-49742021000100019

Figueiredo, A. M., \& Souza, S. R. G. (2008). Como elaborar Projetos, Monografias, Dissertações e Teses: Da redação cientifica à apresentação do texto final. (2. ed.). Rio de Janeiro: Lumen Juris.

Fiori, R., \& Goi, M. E. J. (2020). O Ensino de Química na plataforma digital em tempos de Coronavírus. Revista Thema, 18 (ESPECIAL), 218-242. http://dx.doi.org/10.15536/thema.V18.Especial.2020.218-242.1807 
Flores, J. B., \& Do Rosário Lima, V. M. (2021). Educação em tempos de pandemia: dificuldades e oportunidades para os professores de ciências e matemática da educação básica na rede pública do Rio Grande do Sul. Revista Insignare Scientia-RIS, 4(3), 94-109. https://doi.org/10.36661/2595-4520.2021v4i4.12116

Forte, R. M. O. (2019). O uso das tecnologias no Ensino de Química.

http://www.contadores.cnt.br/noticias/artigos/2019/08/07/o-uso-das-tecnologias-no-ensino-de-quimica

Freitas, A. C. O. (2013). Utilizaçao de recursos visuais e audiovisuais como estrategia no Ensino de Biologia. Monografia (Graduação em Ciências Biológicas à distância) - Centro de Ciencias da Saúde, Universidade Estadual do Ceará, Fortaleza.

Fundação Oswaldo Cruz (Fiocruz). (2021). Como se prevenir contra o coronavírus? https://portal.fiocruz.br/pergunta/como-se-prevenir-contra-o-coronavirus

Gerhardt, T. E., \& Silveira, D. T. (2009). Métodos de pesquisa. (1. ed.). Porto Alegre: Editora da UFRGS.

Godoy, A. S. (1995). Pesquisa qualitativa: tipos fundamentais. Revista de Administração de empresas, 35(3), $20-29$.

Knechtel, M. R. (2014). Metodologia da pesquisa em educação: uma abordagem teórico-prática dialogada. (1. Ed.). Curitiba: Intersaberes.

Laia, S. S. (2016). O poder das imagens didáticas na construção do saber no ensino de ciências. (Trabalho de Conclusão de Curso, Universidade de Brasília, Faculdade UnB Planaltina).

https://bdm.unb.br/bitstream/10483/14161/1/2016 StefanneSouzaLaia tcc.pdf

Leão, D. M. M. (1999). Paradigmas contemporâneos de educação: escola tradicional e escola construtivista. Cadernos de pesquisa, (107), 187-206.

https://www.scielo.br/j/cp/a/PwJJHWcxknGGMghXdGRXZbB/?format=pdf\&lang=pt

Lima, I. P., \& Ferrete, A. A. S. S. (2020). WhatsApp em práticas de ensino e aprendizagem em tempo de pandemia. Anais Educon 2020, São Cristóvão, 14(8), 1-15. http://dx.doi.org/10.29380/2020.14.08.15

Marques, R. C., Silveira, A. J. T., \& Pimenta, D. N. (2020). A Pandemia de COVID-19: interseções e desafios para a história da saúde e do tempo presente. In: Reis, Tiago Siqueira, et al. (Orgs.). Coleção história do tempo presente, volume 3. Boa Vista: Editora da UFRR, pp. 225-249.

https://portal.fiocruz.br/sites/portal.fiocruz.br/files/documentos/a-pandemia-de-covid-19 intersecoes-edesafios-para-a-historia-da-saude-e-do-tempo-presente.pdf

Mélo, C. B., Farias, G. D., Nunes, V. R. R., de Andrade, T. S. A. B., \& Dalle Piagge, C. S. L. (2021). A extensão universitária no Brasil e seus desafios durante a pandemia da COVID-19. Research, Society and Development, 10(3), e1210312991. http://dx.doi.org/10.33448/rsd-v10i3.12991

Miranda, N. F. (2007). Tecnologias digitais no ensino de Química. (Tese de Doutorado, Universidade Federal do Ceará, Faculdade de Educação).

Moreira, J. A., Henriques, S., \& Barros, D. M. V. (2020). Transitando de um ensino remoto emergencial para uma educação digital em rede, em tempos de pandemia. Dialogia, (34), 351-364.

https://doi.org/10.5585/Dialogia.N34.17123

Moreira, J. A., \& Schlemmer, E. (2020). Por um novo conceito e paradigma de educação digital onlife. Revista UFG, 20(26). https://doi.org/10.5216/revufg.v20.63438 
Mota, C. B. (2015). O uso eficiente de apostilas no ensino público e privado. Revista Eletrônica Cientificada FAESB Ano 2, 1(1), 1-10. http://www.faesb.com.br/revista/wp-content/uploads/2015/05/artigo cris 2015.pdf

Neto, E. B. (2017). O ensino híbrido: processo de ensino mediado por ferramentas tecnológicas. Ponto-e-Vírgula: Revista de Ciências Sociais, (22), 59-72.

https://revistas.pucsp.br/pontoevirgula/article/download/31521/24901

Neves, J. L. (1996). Pesquisa qualitativa - características, usos e possibilidades. Caderno de Pesquisas em Administração, 1(3), 1-5.

https://www.academia.edu/8171621/PESQUISA QUALIATIVA CARACTETISTICAS USOS E POSSIBI $\underline{\text { LIDADE }}$

Nunes, R. C. (2021). An overview of the evasion of university students during remote studies caused by COVID-19 pandemic. Research, Society and Development, 10(3), e1410313022.

http://dx.doi.org/10.33448/rsd-v10i3.13022.

OPAS/OMS Brasil. (2021). Folha informativa - COVID-19 (doença causada pelo novo coronavírus). https://www.paho.org/pt/covid19/historico-da-pandemia-covid-19

QuestionPro. (2021). Analise descritiva: o que é, como usá-la em pesquisas.

https://www.questionpro.com/blog/pt-br/analise-descritiva/

Salasse, A. M. T. (2012). A Experimentação no Ensino de Química: importância das aulas práticas no processo de ensino aprendizagem (Monografia de Pós-Graduação, Universidade Tecnológica Federal do Paraná). https://repositorio.unesp.br/bitstream/handle/11449/136634/000860513.pdf

Santana, P. C. (2021). A importância do Ensino de Química e seu conhecimento na formação universitária de profissionais da saúde. https://m.meuartigo.brasilescola.uol.com.br/a-importancia-ensino-quimica-seuconhecimento-na-formacao-universitaria-de-profissionais-saude.htm

Santos Neto, M. B. D., Almeida, S. D. N., \& Feitosa, R. A. (2018). Uso de objetos de aprendizagem para abstração no Ensino de Química: estado da arte. Caminhos da Educação Matemática em Revista/Online, 8(2), 23584750 .

https://aplicacoes.ifs.edu.br/periodicos/index.php/caminhos da educacao matematica/article/download/206 $\angle 170$

Santos, V. (2020). Ensino Remoto: como ficam as devolutivas e feedbacks aos alunos?

https://novaescola.org.br/conteudo/19751/ensino-remoto-como-ficam-as-devolutivas-e-feedbacks-aos-alunos

Secretaria de Estado de Educação e Qualidade de Ensino do Amazonas (Seduc-AM). (2021). Aula em Casa. http://www.educacao.am.gov.br/aula-em-casa/

Silva, V. G. (2016). A importância da experimentação no ensino de química e ciências. (Trabalho de Conclusão de Curso, Universidade Estadual Paulista, Faculdade de Ciências).

Vercelli, L. (2020). Aulas remotas em tempos de covid-19: a percepção de discentes de um programa de mestrado profissional em educação. Revista@mbienteeducaşão, 13(2), 47-60.

https://doi.org/10.26843/https://doi.org/10.26843/ae19828632v13n22020p47a60 